\title{
Effect of losing on early maladaptive schemata of individual male athletes
}

\author{
Servet Reyhan ${ }^{1 \star}$, Yunus Gür ${ }^{2}$ and Mir Hamid Salehian ${ }^{3}$ \\ ${ }^{1}$ Department of Physical Education and Sport Sciences, Siirt University, Turkey. \\ ${ }^{2}$ Institute of Health Sciences, University of Kahramanmaraş Sütçü Imam, Turkey. \\ ${ }^{3}$ Department of Physical Education, Islamic Azad University, Tabriz Branch, Tabriz, Iran.
}

Accepted 23 March, 2020

\begin{abstract}
The purpose of this study was to determine the effect of losing on early maladaptive schemata of individual male athletes. The present study was a descriptive-analytical research method. The statistical population of this study was all male athletes in two age groups of adolescents and young people from individual (weightlifting, tack and taekwondo) who participated in the championship of Erzurum province and country in 2019. According to the statistics, the number of these people was estimated at 2,800 athletes. The statistical sample of this study, based on the sample Morgan table (1970), was 338 athletes. The current research tool was Yang Schema Questionnaire (2003). Data were analyzed using independent t-test by SPSS software version 21 . The results of this study showed that there was a significant difference between early maladaptive schemas among male athletes with a status of lose and sport field.
\end{abstract}

Keywords: Early maladaptive schema, sport, competition, lose.

*Corresponding author. E-mail: serreyhannn@gmail.com.

\section{INTRODUCTION}

Schemes are one of psychological causes of its particular importance in psychology studies. Schemes lead individuals to biases of events interpretations, and these biases show themselves as distorted attitudes, false speculations, unrealistic goals, primitive maladaptive, patterns or deep intrinsic materials that are related to each other's relationship with them or others and are highly ineffective. Young collects a set of layouts that they call initial schemas that are incompatible.

One of the new and important structures that explore the style of cognitive processing and how it affects emotional processing in humans is the structure of early maladaptive schemas. Inappropriate schemas, selfemotional and cognitive emotional patterns in an individual that are formed in the early stages of development and evolved in the mind, are repeated in the path of life (Young et al., 1999).

Initial maladaptive schemas arise because of the lack of basic emotional needs of childhood. Fundamental needs, such as secure attachment to others, self- regulation, freedom to express healthy needs and emotions, spontaneity and realistic constraints (Taliaferro et al., 2011). These schemas operate at the deepest level of knowledge, usually out of the level of consciousness, and make the person psychologically more vulnerable to creating disturbances such as depression, anxiety, ineffective communication, addiction and mental disorders (Young et al., 1999).

The proposed scheme by Young is divided into five areas: cuts and exclusion, self-regulation and impaired performance, impaired limits, other orientation, overheard and inhibition (Young et al., 1999). When these schemas are activated, they can affect perception, reality, and cognitive processing (Connor-Smith and Flachsbart, 2010).

In this way, current researches have determined that schemas has effective in cognitive processing, making one more vulnerable to psychological damage. One of the areas that is expected to trigger maladaptive schemas to lead to cognitive impairment, resulting in 
mental and mental disturbance, is an area of interest, but by reviewing the research literature it becomes clear that it is less likely to examine the relationship between schemas that are incompatible with some sports have been addressed to issues such as athletes' wins and losses.

The functions of exercise in different fields have always been one of the areas of interest to researchers. One of the issues of nature in sports is winning and losing. The role of the loss in sporting competitions has always been an attempt on some psychological characteristics of athletes, including early maladaptive schemas. This has led to efforts by some researchers to attempt to take on the role and the loss of initial maladaptive schemas.

On the other hand, there is a need for comprehensive research in this area, especially studies on various sports fields to this end, the aim of the present study was to design and implement the effects of winning and losing on early maladaptive schemas of male athletes in different levels of competition.

One of the psychological factors involved in the selection and use of coping strategies is athletic personality traits. Research evidence suggests that extraversion athletes who are emotionally stable and open to new experiences are more likely to use problemsolving strategies. Also, athletes with athletes and athletes who enjoy extraversion, openness and high level of acceptance benefit from more emotional coping strategies. In addition, athletes who have low levels of openness or high levels of psychosocial depression use more avoidance strategies (Backer and Beech, 2004).

Pincus and Lukowitsky (2010) showed that among the early maladaptive schemas, levels of emotional deprivation schemes, emancipation/insecurity, lack of trust/mistreatment, failure, attachment/baccalaureate, acceptance/ attraction, and the punishment of female rugby players is higher than that of handball players who have an impact on the athlete's athletic level on the level of maladaptive schemas. From all this evidence, it can be concluded that winning and losing at different competitive levels may have a different effect on the activation of early maladaptive schemas, that is, each one may be specific domains of incompatible schemas Activate the primary.

Research evidence suggests that narcissism is associated with aggression, ethical restraint and antisocial behaviors of athletes, which emphasizes the necessity of a detailed study (2001) and the probable role of narcissism in employing coping strategies. The present research seeks to answer this question. Are the dimensions of narcissism and the strategies of coping with competitive stress in the elite athletes? This structure and its role in athletic attitudes are emphasized at various competitive levels (Jones et al., 2011). Considering the key role of emotional control and stress coping strategies in performance and athletic performance (Nicholls and Polman, 2001), the role of probabilistic narcissism in the application of stress coping strategies. The present research seeks to answer the question of whether the narcissistic dimensions and coping strategies of competitive stress in elite athletes are related. For example, the study of narcissism in soccer players shows that narcissism is negatively correlated with extroversion and psychosocial disorder and has a negative relationship with psychosis (Anderson et al., 2006). From the overview of the above evidence, the question arises as to whether adolescent involvement in using competitive coping strategies in athletes may be involved.

Therefore, due to the lack of clear understanding of the above issues, the present research attempts to answer this question whether loss at different competitive levels (provincial and national) would affect the early maladaptive schemata of young male athletes in individual disciplines or not.

\section{MATERIALS AND METHODS}

The present research is a descriptive-analytical (posttrait) research method. In terms of purpose, the present research is a type of applied research, and in terms of time, it is a kind of retrospective research.

\section{Statistical society}

The statistical population of the present study was all male athletes in two age groups of adolescents and youth from individual disciplines (weightlifting and Taekoeandow) who participated in the championship in the province of Erzurum and the country in 2018. In this study, according to the provincial and national sporting competitions, there are an average of 300 athletes per year in provincial adolescents and youth competitions and 500 athletes in national adolescents and youth competitions. Based on this, the estimated statistical population of 2800 athletes was estimated.

\section{Statistical sample}

The statistical sample of this study was 346 samples based on the size of the sample size set by Krejci and Morgan (1970). Samples were selected using simple stratified random sampling.

\section{Measuring instruments research}

Individual Information Form: A researcher-made form consists of eight materials to determine the demographic characteristics of the age, the number of family members, the level of parental education, the sport's history, the 
field of sport, the record, the history of the championship and the status of the final win and loss.

\section{Young scheme questionnaire - short form (YSQ-SF)}

This questionnaire was developed by Young et al. (2003) and consists of 75 statements to measure 15 initial maladaptive schemas, whose responses are scored on a six-point Likert continuum. The grades for the score are 1 = completely false, 2 = more false, 3 = somewhat incorrect, $4=$ almost correct, $5=$ more correct, and $6=$ perfectly correct. A higher score in this tool suggests that there are higher inconsistent cognitive schemas. The internal consistency of the questionnaire was 0.79 and 0.98 for women using Cronbach's alpha coefficient.

\section{Data collection method}

The information needed in this study was collected using field method. In this way, after obtaining the necessary licenses for the Department of Sport and Youth and Sport Federations, the fields studied and receiving the program of the championship of the province and the country competitions, the researcher has been present at the venue of the competitions and with observing methodological considerations, attempted to collect sample and information.

\section{General manner of implementation}

The required information in the present study was collected by field method and was collected during the period of July 2018 to January 2019. After obtaining the necessary permissions from the General Department of Sports and Youth and Sport Federations, the fields studied and the program for holding the championship of the province and the country in the male's ward and in two age groups of youth, researcher at the venue of the competition attending and observing methodological considerations, sampling was done in the field of athletics and Taekwondo.

Prior to the time of each competition, in order to draw the cooperation of the supervisors and coaches of the participating teams to provide the appropriate time to collect information, a description of the research objectives and the necessity of its implementation was presented by the researcher. The time for completion of the questionnaires was considered after the end of the competition.

In the sampling, the participants tried to combine successful athletes and unsuccessful teams in the competition. From athletes and teams volunteering to participate in the study, they were invited to attend the designated times at the designated venue. At first, explanations about the research goals and its necessity, the questionnaire completion method, the confidentiality of the collected information and the availability of the company in the research were presented and the packages were provided to them.

\section{Statistical analysis methods}

Independent t-test was used to compare the mean of early maladaptive schemas in different groups. Data were analyzed using SPSS software version 20 .

\section{RESULTS}

According to the results of the study, it was found that the win athletes' group had a lower range of mean in incompatible schema of emotional deprivation, incompatible relapse/ instability, incompatibility of mistrust/ mistreatment, social isolation/ alienation, defect/ shame, failure, attachment/ incompetence, vulnerability to harm and illness, self-evolved/ self-inflicted, obedience, self-sacrifice, emotional inhibition, extreme cruelty/ extreme defamation, destitution/ great secretary, selfrestraint/inadequate self-discipline (Table 1). Considering the significance level below 0.05 , it was found that this difference is significant.

\section{DISCUSSION AND CONCLUSION}

According to the results of research, it was found that there is a significant difference between the initial and maladaptive schemata among athletes with a status of win and loss. The study of the mean of early maladaptive schemas showed that the athlete group had a lower range than the average initial maladaptive schema. Regarding the significance level, which was lower than 0.05 in all components, it was found that this difference is significant. This issue in all components of early maladaptive schemas includes emotional deprivation, emancipation/instability, mistrust/ mistreatment, social isolation/alienation, social isolation/alienation, failure, dependence/incompetence, vulnerability to disease and disease, self-evolution unrecognized/self-caught, objection, sacrifice, emotional restraint, extreme cruelty/extreme defamation, decent deservedness/ selfrestraint/ insolvency were inadequate, and with the increase in status, the amount of these components diminished.

A little research has been done on this issue. Bamber and McMahon (2008) found in their research that individual successes would reduce the amount of initial maladaptive schemas. Kirsch (2009) also found that achieving success through self-esteem would reduce the amount of early maladaptive schemas. This indicates this 
Table 1. Study of early maladaptive schemas of male athletes in terms of win and losses.

\begin{tabular}{|c|c|c|c|c|c|}
\hline Variable & Groups & $\mathbf{M}$ & Std. Er. & $\mathbf{T}$ & $\mathbf{P}$ \\
\hline Initial incompatible schema & $\begin{array}{l}\text { Win } \\
\text { Loss }\end{array}$ & $\begin{array}{l}3.41 \\
3.70\end{array}$ & $\begin{array}{l}0.462 \\
0.637\end{array}$ & 6.001 & 0.001 \\
\hline Inconsistent Emotional Exclusion Scheme & $\begin{array}{l}\text { Win } \\
\text { Loss }\end{array}$ & $\begin{array}{l}3.30 \\
3.72\end{array}$ & $\begin{array}{l}0.501 \\
0.612\end{array}$ & 7.621 & 0.001 \\
\hline Inconsistent Scheme of Abandonment / Instability & $\begin{array}{l}\text { Win } \\
\text { Loss }\end{array}$ & $\begin{array}{l}3.15 \\
3.35\end{array}$ & $\begin{array}{l}0.712 \\
0.863\end{array}$ & 7.010 & 0.001 \\
\hline Incompatible Scheme of Mistrust / Abuse & $\begin{array}{l}\text { Win } \\
\text { Loss }\end{array}$ & $\begin{array}{l}3.45 \\
3.67\end{array}$ & $\begin{array}{l}0.446 \\
0.724\end{array}$ & 6.712 & 0.001 \\
\hline Incompatible schema of social isolation / alienation & $\begin{array}{l}\text { Win } \\
\text { Loss }\end{array}$ & $\begin{array}{l}3.70 \\
3.30\end{array}$ & $\begin{array}{l}0.462 \\
0.637\end{array}$ & 0.762 & 0.001 \\
\hline Incompatible Scheme Defamation / Shame & $\begin{array}{l}\text { Win } \\
\text { Loss }\end{array}$ & $\begin{array}{l}3.72 \\
3.15\end{array}$ & $\begin{array}{l}0.501 \\
0.612\end{array}$ & 0.501 & 0.001 \\
\hline Incompatible schema failed & $\begin{array}{l}\text { Win } \\
\text { Loss }\end{array}$ & $\begin{array}{l}3.70 \\
3.30\end{array}$ & $\begin{array}{l}0.712 \\
0.863\end{array}$ & 0.712 & 0.001 \\
\hline Incompatible schema of dependency / incompetence & $\begin{array}{l}\text { Win } \\
\text { Loss }\end{array}$ & $\begin{array}{l}3.72 \\
3.15\end{array}$ & $\begin{array}{l}0.446 \\
0.724\end{array}$ & 0.446 & 0.001 \\
\hline Incompatible schema of vulnerability to disease & $\begin{array}{l}\text { Win } \\
\text { Loss }\end{array}$ & $\begin{array}{l}3.35 \\
3.45\end{array}$ & $\begin{array}{l}0.462 \\
0.637\end{array}$ & 0.462 & 0.001 \\
\hline Self-perpetuating, incompatible schema & $\begin{array}{l}\text { Win } \\
\text { Loss }\end{array}$ & $\begin{array}{l}3.70 \\
3.30\end{array}$ & $\begin{array}{l}0.501 \\
0.612\end{array}$ & 0.512 & 0.001 \\
\hline An incompatible schema of obedience & $\begin{array}{l}\text { Win } \\
\text { Loss }\end{array}$ & $\begin{array}{l}3.45 \\
3.70\end{array}$ & $\begin{array}{l}0.712 \\
0.863\end{array}$ & 0.712 & 0.001 \\
\hline An incompatible schema of self-sacrifice & $\begin{array}{l}\text { Win } \\
\text { Loss }\end{array}$ & $\begin{array}{l}3.30 \\
3.45\end{array}$ & $\begin{array}{l}0.446 \\
0.724\end{array}$ & 0.616 & 0.001 \\
\hline Inconsistent Emotional Restraint Schema & $\begin{array}{l}\text { Win } \\
\text { Loss }\end{array}$ & $\begin{array}{l}3.70 \\
3.70\end{array}$ & $\begin{array}{l}0.462 \\
0.637\end{array}$ & 0.562 & 0.001 \\
\hline An Incompatible Scheme of Extreme Hardness / Extreme fraud & $\begin{array}{l}\text { Win } \\
\text { Loss }\end{array}$ & $\begin{array}{l}3.30 \\
3.72\end{array}$ & $\begin{array}{l}0.501 \\
0.612\end{array}$ & 0.601 & 0.001 \\
\hline Wrong incompatible schema / large secretary & $\begin{array}{l}\text { Win } \\
\text { Loss }\end{array}$ & $\begin{array}{l}3.15 \\
3.45\end{array}$ & $\begin{array}{l}0.712 \\
0.863\end{array}$ & 0.712 & 0.001 \\
\hline Inadequate self-discipline / incompatible schemas & $\begin{array}{l}\text { Win } \\
\text { Loss }\end{array}$ & $\begin{array}{l}3.70 \\
3.30 \\
\end{array}$ & $\begin{array}{l}0.446 \\
0.724\end{array}$ & 0.606 & 0.001 \\
\hline
\end{tabular}

is important. The results of this study are consistent with the results of this study with the results of Bamber and McMahon's (2008) and Kirsch research (2009).

In the interpretation of this result, it should be noted that winning and losing in sports contests play an important role in the minds of athletes. There is no doubt that an athlete is not happy with his winnings and will not be upset by his loss. This has led to an increase in efforts among athletes in pursuit of sporting success. The same efforts, if accompanied by negative and negative results, cause athletes to feel depressed, anxious and stressed. It will be natural for the athletes to lose some of their negative psychological characteristics.

Hence, it can be stated that the issue of winning and losing due to the close relationship with all aspects of athletes will play an important role in creating or not creating early maladaptive schemas. This issue has led to the loss of athletes in the present study with a more 
initial maladaptive schema than the athletes with a status winning.

This issue in all components of the early maladaptive schemas includes an inconsistent schema of emotional deprivation, emancipation/instability, mistrust/mistreatment, social isolation/alienation, social isolation/alienation, failure, attachment/incompetence, vulnerability to disease and disease, self-evident self-esteem, obedience, selfsacrifice, emotional restraint, extreme cruelty/extreme defamation, privilege/great secretary, and incompatible self-respect/self-discipline schema.

\section{REFERENCES}

Anderson, K., and Rieger, E. Caterson I. (2006). A comparison of maladaptive schemata in treatment-seeking obese adults and normal-weight control subjects. Journal of Psychosomatic Research, 60(3): 245-252.

Backer, E., and Beech, A. R. (2004). Dissociation and variability of adult attachment dimentions and early maladaptive schemas in sexual and violent offenders. Journal of Interpersonal Violence, 10 (10): 119-125.

Bamber, M., and McMahon, R. (2008). Danger-early maladaptive schemas at work! The role of early maladaptive schemas in career choice and the development of occupational stress in health workers. Clinical Psychology and Psychotherapy, 15(2): 96-112.

Connor-Smith, J. K., and Flachsbart, C. (2007). Relations between personality and coping: A meta-analysis. Journal of Personality and Social Psychology, 93: 1080-1107.

Jones, B., Woodman, J. P., Barlow, M., and Roberts, R. (2017). The darker side of personality: Narcissism predicts moral disengagement and antisocial behavior in sport. Sport Psychologist, 31(2): 109-116.

Kirsch, J. (2009). Early maladaptive schemas, self-esteem, and changes in depression and anxiety in young adults during residential substance abuse treatment (doctoral dissertation), Widener University, Chester, Pennsylvania.

Krejcie, R. V., and Morgan, D. W. (1970). Determining sample size for research activities. Educational and Psychological Measurement, 30: 607-610.

Nicholls, A. R., and Polman, R. C. J. (2007). Coping in sport: A systematic review. Journal of Sports Sciences, 25(1): 11-31.

Taliaferro, L. A., Eisenberg, M. E., Johnson, K. E., Nelson, T. F., and Neumark-Sztainer, D. (2011). Sport participation during adolescence and suicide ideation and attempts. International Journal of Adolescent Medicine and Health, 23(1): 3-10.
Pincus, A. L., and Lukowitsky, M. R. (2010). Pathological narcissism and narcissistic personality disorder. Annual Review of Clinical Psychology, 6: 421-446.

Young, J., Colosseo, J., and Vishar, M. (2010). Schema Therapy (Practical Guide for Professionals). Arjmand Publications.
Citation: Reyhan, S., Gür, Y., and Salehian, M. H. (2020). Effect of losing on early maladaptive schemata of individual male athletes. African Educational Research Journal, 8(1): 78-82. 